\title{
Developing Postoperative Nursing Care Standards for Patients Undergoing High Tibial Osteotomy Surgery
}

\author{
Soad M. Sayed, Hala M. Ghanem, Attyiat H. Hussein \& Mohamed M. Abd Alhameid.
}

Nursing Supervisor on Orthopedic surgery department Assiut University Hospital Egypt.

Assistant professor of medical-surgical Nursing, Adult Nursing Department, Faculty of Nursing ,Assiut University

Egypt.

Lecturer of medical-surgical Nursing, Adult Nursing Department, Faculty of Nursing ,Assiut University Egypt.

Professor of Orthopedic and Traumatology surgery, Faculty of Medicine, Assiut University Egypt.

\begin{abstract}
High tibial osteotomy an osteotomy is an operation where a bone is cut and re-positioned. The aim of this study explores and developing postoperative nursing care standards for patients undergoing high tibial osteotomy surgery. Subject and methods: Descriptive exploratory research design was utilized. The study was carried out in the department of orthopedic surgery at Assiut University Hospital. The study sample of all available nurses working in orthopedic department and who are willing to participate in this study (30).Tools utilized for data collections were Nurse's questionnaire sheet, Observation nursing practice checklist sheet and post-operative basic competencies Opinionnaire sheet. Results showed the knowledge about standards of post operative interventions for high tibial osteotomy patients, more than half of nurses $(53.3 \%)$ had good knowledge regarding standards of post operative interventions for high tibial osteotomy patients. Nurses showed inadequacy in their practice about standards of post operative interventions for high tibial osteotomy patients .majority of nurses agree with basic post-operative nursing care standards. Conclusion: Formulation of standards is the first step toward evaluating nursing care delivery. Recommendation: an In-service training program for nurses is important in orthopedic surgery department. Application of the nursing care standards for post-operative high tibial osteotomy patients.
\end{abstract}

Keyword: High Tibial Osteotomy, Standards \& Nursing.

\section{Introduction}

High tibial osteotomy an osteotomy is an operation where a bone is cut and Re-positioned. In a high tibial osteotomy, the bone of the upper tibia is cut and regulated to realign the leg. This reduces the pain that is experienced in the knee by taking pressure off the damaged joint compartment. (Wolcott \& Traub, 2010).

Patients younger than 50years would be better suited for osteotomy with the intention of "buying time" before knee replacement are required. For patients between 50 and 60 years, a decision has to be made based on activity level, expectations, and degree of degeneration (Amendola \&Bonasia, 2010).

This standard of care guidelines for patients have undergone high tibial osteotomy(HTO) secondary to early medial compartment joint space narrowing or chondral defects and present with the following impairments: Pain, Impaired flexibility at the knee, Impaired strength, an Impaired function related to sports, and impaired gait (Aalderink \&Shaffer, 2010).

Indications for high tibial osteotomy fall into two main groups: (a) unloading a compartment suffering from early degenerative change, and (b) controlling instability of the knee resulting from specific ligamentous laxities. The goal of osteotomy is to relieve pain, improve function, and slow down the degenerative process (Brosset \&Psaquier, 2011).

All patients are at risk of complications following surgery, but complications do not occur frequently. The following are the main important complications: Anesthetic complications are extremely rare other than some postoperative dizziness and nausea. Pain after surgery, pain should be controlled using medication. Nerve and blood vessel damage the surgical area is near a number of nerves and blood vessels. Injury to these nerves or vessels can occur (less than one in 300 patients). Swelling and numbness due to the nature of the surgery there will be some swelling of the leg this usually reduces over about two weeks. (Rossi\& Bonasia, 2011).

An infection this can be a serious complication but if it is usually picked up early is easily treated. repeated , compartment syndrome this needs to be identified early when there is disproportionate pain and excessive swelling an early return to the theatre may be required to relieve the pressure built up in the leg. Deep Vein Thrombosis( DVT) clots in the deep veins of the calf can be serious, Slippage or loosening of the plates and screws although this is rare, adherence 
to the postoperative regime of limited weight-bearing and crutch usage limits this risk Non-union this is when the bone fails to unite, although it is very rare, as the bone in this area has a good blood supply If this does happen further procedures, including bone grafting, may be necessary. (Rossi\& Bonasia, 2011).

Nurses play an important role for patients who had high tibial osteotomy. The nurse will take frequent observations of vital signs, wound, drains and limb (cooler, warmth, sensation, and movement) for several hours after the surgery. Rehabilitation will be needed therapy that includes the use of crutches, and range of motion exercises. The nurses give instruction about Non-weight bearing with crutches to reduce pain and swelling. (Brouwer\& Bierma, 2006)

One goal of high tibial osteotomy is to alter the history of underlying osteoarthritis by unloading the articular surfaces (Wrigh\&Crockett,2005).

High tibial osteotomy is a reasonable alternative to Total Knee Arthoplasty(TKA )in the younger patient population with osteonecrosis of the medial femoral condoyle and may lead to regression of the disease. It is also used in younger patients with osteochondritis dessicans of the medial femoral condoyle who have not improved with conservative treatment (Hoell \&Suttmeller ,2005).

This surgical procedure is commonly used in the younger patient population who want to be able to maintain a high activity level upon recovery. unicompartmental arthritic changes are becoming more abundant in the younger patient population ranging in age from patients in their twenties to forties due to a high interest in sports. High tibial osteotomy is best utilized when the patient is a nonsmoker, has body weight less than 1.32 times normal, ROM in the affected knee is greater or equal to 90 degrees, and when the arthritic changes are limited to the medial compartment (Hartford \& James, 2003).

This procedure has been found to be a safe treatment and a technique that can be reproducible. It allows for future knee reconstruction to occur if needed. There is increased interest in the surgical technique secondary to cartilage repair procedures failing in the setting of malalignment of the lower extremity. High tibial osteotomy decreases knee pain, allows higher activity levels post operatively and a much-improved quality of life2. Once the patient has recovered from the procedure and the osteotomy has healed sufficiently, there are typically no activity restrictions for the patient (Brouwer \&Bierma,2006).

Standards of care are authoritative statements that detail plans of care for individuals with a specific health problem. A standard of care covers a broader range of concerns for the individual than does a protocol The purpose of a standard of care is to establish the best practice and eliminate as much variation as possible. Standards of care often include aspects of medical care and various therapies as well as nursing care. They identify specific desired outcomes for each day of hospitalization and actions that are to be taken to achieve those outcomes. (Janice \&Celia, 2009)

Standards of nursing practice are authoritive statements that describe a common or acceptable level of professional nursing performance. Standards of practice, therefore, define professional practice. The American Nurses Association (1991) has developed general standards and guidelines for nursing practice that apply across the nation and are broad and general in nature. (Dianna, 2010)

\section{Significance of the study}

Through a period of several years working in the orthopedic department at Assiut University Hospitals, the researcher observed that the patients with high tibial osteotomy needed a special nursing care to improve the patient's outcome. This study was the first study that provides a standard of nursing care in this geographical location which helped such groups of health care provider to provide nursing care standards.

\section{Aim of the study}

The aim of this study is to explore and developing postoperative nursing care standards for patients undergoing high tibial osteotomy surgery.

\section{Subjects \& methods}

\section{Research design}

Descriptive exploratory research design was utilized in this study.

\section{Technical design}

Setting: the study was conducted in orthopedic surgery department at Assiut University Hospital. Subjects

A convenience sample of all available nurses(30) working in orthopedic surgery department and who were to participate in this study.

Tools

Three tools were collected in this study and developed by the researcher based on current national and international literature to collect the necessary data for this study.

Tool I: Nurse's questionnaire sheet

This tool to assess nurses' knowledge, and practice about post-operative nursing care standards for a patient undergoing high tibial osteotomy surgery .It included two parts. 


\section{Part (I): Socio-demographic data}

This part comprised nurse's name, age, sex, marital status, the level of education, years of experience and previous attending training opportunities about high tibial osteotomy surgery.

Part (2): Nurse's knowledge about high tibial osteotomy surgery

It consists of the definition of high tibial osteotomy surgery, indication, contraindication, management, complications, and nursing care and instruction for patients.

\section{Scoring system}

The total number of questions was (24). The total scores were (100). Those who obtained less than $50 \%$ were considered having a poor level. While those who obtained $50-70 \%$ were considered having a fair level and those who obtained more than $70 \%$ were considered having a good level.

Tool II: Observation nursing practice checklist Sheet: It consists of:

\section{Immediate post-operative nurses practice}

It included assessment of patient's respiratory function, patient's circulatory, thermoregulatory, neurological, gastrointestinal and elimination function and level of comfort.

\section{Routine post-operative nurses practice}

It included the following: relieving pain, wound care, Transfer to a wheelchair, using of knee Brace, using of knee immobilizer, using of cold application, apply exercise, using of crutches, the precaution of postoperative complications.

\section{Before discharge nurses instructions}

It includes health education before discharge regarding Showering, Dressing, Elevation, Ice, Crutches, Medication, Home modification, Diet, exercise, recognition of complications and follow-up care.

Scoring system

Each item in checklist was scored as follow: two degrees for each step that done correct (correctly, in time and with the required frequency) and one degree for each step done incorrect (incorrectly, not in time and without the required frequency) and zero for the step that not done. Inapplicable means that the nurses were not able to apply the principles of the standard due to a shortage of supplies and equipment, not due to shortage or negligence from the nurses.

Tool III: Post-operative nursing care standards Opinionnaire sheet for nurses (PCOS)

It was developed by the researcher based on current national and international literature in order to elicit opinions of nurses as regard to the basic nursing competencies for post-operative high tibial osteotomy patients.

This tool covered 7 major broad competencies which were further subdivided into sub-competencies
- Ensure that the orthopedic surgery department environment are ready to receive the high tibial osteotomy patient

- Ensure that the orthopedic surgery department environment is safe to receive high tibial osteotomy patients.

- Ensure that continuous monitoring and recording are followed for post-operative patients.

- Ensure that all infection control measures are properly followed in all procedures.

- Ensure that all health team is properly attired for patient care.

- Ensure that safety for each patient during transportation from operating room to department.

- Ensure that all staff (health team) follow ethics and patients right in the orthopedic surgery department.

- The scoring system of the nurses Opinionnaire was as follow

\begin{tabular}{|l|c|}
\hline \multicolumn{1}{|c|}{ Competencies } & Score \\
\hline Agree & 1 \\
\hline Disagree & 0 \\
\hline
\end{tabular}

\section{Methods}

A review of current and past, local and international related literature in the various aspects of the problems using books, articles, periodicals, and magazines was done. The proposed study setting was assessed for the numbers of nurses and patients in orthopedic surgery department at Assiut University Hospital.

Content validity was established by panel of 5 expertise's who reviewed the instruments for clarity, relevance, comprehensiveness, understanding, applicability and easiness for administrative minor modifications were required. The content validity of this tool was checked by expert professors in fields of medicine and nursing and correction were carried out accordingly.

A pilot study carried out to test the feasibility and practicability of the study tools on $10 \%$ of sample. It had also provided an estimate of time needed to fill out the tools. The purpose of the pilot study was:

To ascertain the relevance of the tools to detect any problem peculiar to the statements clarity that might interfere with the process of data collection to estimate the time needed to complete the interview schedule

An official letter was issued from the Dean of the Faculty of Nursing to the Head of orthopedic surgery department the necessary approval to conduct the present research. After explaining the aim of the study and the program to them to obtain their cooperation.

Data were collected from orthopedic surgery department and at Assiut University Hospital during the period from August /2014 to December 2014 The tools filled through interviewing. The purpose of the 
study was explained to the nurses prior to answering the questions. The study was carried out at morning, afternoon shifts and night shift

Each nurse was informed of the purpose of the study. The investigator emphasized that the participation is voluntary .Verbal consent was obtained from nurse prior to her contribution in the present study.

The questionnaire was conducted by the researcher using ( a tool I) to elicit opinions of the nurses regarding the required basic competencies.

The basic competencies were formulated in a form of standards and criteria for measuring standards of post operative interventions for high tibial osteotomy patients in the following steps:

- Identifying the scope of knowledge and skills required from nurses for interventions of patients with high tibial osteotomy surgery ( a tool I).

- Determine the framework of the standards "the process standard and structure standard" were used since it describe what the nurse does, assessment techniques and procedures, methods of delivery of care, methods of intervention, preparing the orthopedic surgery department with necessary equipment and methods of recording.

- Determine the level of the standards. In this study, the basic level was used, that is to say, minimally acceptable level of practice needed by orthopedic surgery department nurses for post operative interventions of high tibial osteotomy patients( a tool I).

- Developing tools to determine the level of achievement for the standards, evaluation, in this study assessment of Nurses practice observation checklist and Nurse's questionnaire sheet were developed.

\section{Statistical design}

Data was collected \&analyzed by a computer programmed Spurs. Using necessary statistical manipulation as; number, percentage, mean\& standard deviation to determine significant for variables-value was considered to be significant if less than 0.05 , high significant if less than 0.01 , or insignificant if more than 0.05 .

\section{Limitation of the study}

A lot of barriers during collecting data concerning the thesis about the assessment of nurse's knowledge and practice related to high tibial osteotomy surgery at Assiut University Hospital. Barriers such as some nurses saying what is the benefit of this, and this was reflected on filling the evaluation sheet that makes us retain for them again, and some also neglect to fill in forms. Filling in the observation sheet took along time because observation includes immediate, routine and before discharge of Patients. Most nurses do not understand what the meaning of standards and not understand opinionnaire sheet so explaining took long time. 


\section{Results}

Table 1: Frequency distribution of Socio-demographic characteristics of the studied nurses (NO 30).

\begin{tabular}{|c|c|c|}
\hline Variables & No. & $\%$ \\
\hline \multicolumn{3}{|l|}{ Age (years) } \\
\hline$<20$ & 0 & 0 \\
\hline $20-40$ & 17 & 56.7 \\
\hline$>40$ and more & 13 & 43.3 \\
\hline \multicolumn{3}{|l|}{ Sex } \\
\hline Male & 5 & 16.7 \\
\hline Female & 25 & 83.3 \\
\hline \multicolumn{3}{|l|}{ Marital status } \\
\hline Single & 1 & 3.33 \\
\hline Married & 27 & 90.0 \\
\hline Divorced & 1 & 3.33 \\
\hline Widow or widower & 1 & 3.33 \\
\hline \multicolumn{3}{|l|}{ Level of education } \\
\hline Diploma of nursing & 21 & 70.0 \\
\hline Special diploma of nursing & 3 & 10.0 \\
\hline Technical nursing & 2 & 6.7 \\
\hline Bachelor of nursing & 4 & 13.3 \\
\hline \multicolumn{3}{|l|}{ Years of experience } \\
\hline $1-5$ years & 3 & 10.0 \\
\hline$>5$ years and more & 27 & 90.0 \\
\hline \multicolumn{3}{|l|}{ Attending training courses } \\
\hline Yes & 1 & 3.3 \\
\hline No & 29 & 96.7 \\
\hline
\end{tabular}

Table (2): Part II: Frequency and percentages distribution Nurses' knowledge as regarding postoperative nursing care standards for high tibial osteotomy surgery(NO.30).

\begin{tabular}{|l|c|c|}
\hline \multicolumn{1}{|c|}{ Knowledge level } & No. & \% \\
\hline Poor $(<\mathbf{5 0 \%})$ & 5 & 16.7 \\
\hline Fair(50-70\%) & 9 & 30.0 \\
\hline Good(>70\%) & 16 & 53.3 \\
\hline Total & 30 & 100.0 \\
\hline
\end{tabular}

Table(3): Relationship between total knowledge level of the studied nurses and socio-demographic characteristics (NO.30).

\begin{tabular}{|c|c|c|c|c|c|c|c|}
\hline \multirow{3}{*}{ Variables } & \multicolumn{6}{|c|}{ Knowledge level } & \multirow{3}{*}{ P. value } \\
\hline & \multicolumn{2}{|c|}{ Poor $(n=5)$} & \multicolumn{2}{|c|}{ Fair $(n=9)$} & \multicolumn{2}{|c|}{ Good $(n=16)$} & \\
\hline & No. & $\%$ & No. & $\%$ & No. & $\%$ & \\
\hline \multicolumn{8}{|l|}{ Age } \\
\hline$<20$ & 0 & 0 & 0 & 0.0 & 0 & 0.0 & \\
\hline $20-40$ & 1 & 100.0 & 3 & 42.9 & 13 & 59.1 & \multirow{2}{*}{$0.506^{\mathrm{ns}}$} \\
\hline$>40$ and more & 0 & 0.0 & 4 & 57.1 & 9 & 40.9 & \\
\hline \multicolumn{8}{|l|}{ Sex } \\
\hline Male & 0 & 0.0 & 2 & 28.6 & 3 & 13.6 & \multirow{2}{*}{$0.589^{\text {ns }}$} \\
\hline Female & 1 & 100.0 & 5 & 71.4 & 19 & 86.4 & \\
\hline
\end{tabular}




\begin{tabular}{|c|c|c|c|c|c|c|c|}
\hline \multirow{3}{*}{ Variables } & \multicolumn{6}{|c|}{ Knowledge level } & \multirow{3}{*}{ P. value } \\
\hline & \multicolumn{2}{|c|}{ Poor $(n=5)$} & \multicolumn{2}{|c|}{ Fair $(n=9)$} & \multicolumn{2}{|c|}{ Good $(n=16)$} & \\
\hline & No. & $\%$ & No. & $\%$ & No. & $\%$ & \\
\hline \multicolumn{8}{|l|}{ Marital status } \\
\hline Single & 0 & 0.0 & 0 & 0.0 & 1 & 4.5 & \multirow{4}{*}{$0.976^{\mathrm{ns}}$} \\
\hline Married & 1 & 100.0 & 7 & 100.0 & 19 & 86.4 & \\
\hline Divorced & 0 & 0.0 & 0 & 0.0 & 1 & 4.5 & \\
\hline Widow or widower & 0 & 0.0 & 0 & 0.0 & 1 & 4.5 & \\
\hline \multicolumn{8}{|l|}{ Level of education } \\
\hline Diploma of nursing & 0 & 0.0 & 5 & 71.4 & 16 & 72.7 & \multirow{4}{*}{$0.083^{\mathrm{ns}}$} \\
\hline Special diploma of nursing & 0 & 0.0 & 2 & 28.6 & 1 & 4.5 & \\
\hline Technical nursing & 0 & 0.0 & 0 & 0.0 & 2 & 9.1 & \\
\hline Bachelor of nursing & 1 & 100.0 & 0 & 0.0 & 3 & 13.6 & \\
\hline \multicolumn{8}{|l|}{ Years of experience } \\
\hline $1-5$ years & 1 & 100.0 & 0 & 0.0 & 2 & 9.1 & \multirow{2}{*}{$0.007 * *$} \\
\hline$>5$ years & 0 & 0.0 & 7 & 100.0 & 20 & 90.9 & \\
\hline
\end{tabular}

Table (4):Frequency and percentage distribution of nurses practice level of the studied nurses (NO.30).

\begin{tabular}{|c|c|c|c|c|c|c|c|c|}
\hline \multirow{2}{*}{ Variables } & \multicolumn{2}{|c|}{$\begin{array}{c}\text { Done } \\
\text { correct }\end{array}$} & \multicolumn{2}{|c|}{$\begin{array}{c}\text { Done } \\
\text { incorrect }\end{array}$} & \multicolumn{2}{|c|}{ Not done } & \multicolumn{2}{|c|}{ NA } \\
\hline & No. & $\%$ & No. & $\%$ & No. & $\%$ & No. & $\%$ \\
\hline Assessment of nurse's hand washing & 8 & 26.7 & 10 & 33.3 & 12 & 40.0 & 0 & 0.0 \\
\hline \multicolumn{9}{|l|}{ Immediate post-operative care } \\
\hline $\begin{array}{l}\text { Assess the level of consciousness frequently by } \\
\text { GCS }\end{array}$ & 10 & 33.3 & 7 & 23.3 & 13 & 43.3 & 0 & 0.0 \\
\hline Apply oxygen as needed & 5 & 16.7 & 1 & 3.3 & 24 & 80.0 & 0 & 0.0 \\
\hline positioning of patient & 15 & 50.0 & 5 & 16.7 & 10 & 33.3 & 0 & 0.0 \\
\hline $\begin{array}{l}\text { check urinary catheter, wound site and } \\
\text { administer I.V infusions and medication }\end{array}$ & 11 & 36.7 & 13 & 43.3 & 6 & 20.0 & 0 & 0.0 \\
\hline $\begin{array}{l}\text { Report and assist in management of any post- } \\
\text { operative complications and Document all data } \\
\text { and relevant information }\end{array}$ & 16 & 53.3 & 4 & 13.3 & 10 & 33.3 & 0 & 0.0 \\
\hline $\begin{array}{l}\text { Assessment of nurse's vital signs practice } \\
\text { observation checklist about post-operative care } \\
\text { of high tibial osteotomy surgery }\end{array}$ & 10 & 33.3 & 5 & 16.7 & 15 & 50.0 & 0 & 0.0 \\
\hline $\begin{array}{l}\text { Assessing the respiration rate and depth and } \\
\text { character }\end{array}$ & 1 & 3.3 & 1 & 3.3 & 28 & 93.3 & 0 & 0.0 \\
\hline Assessing pulse rate & 1 & 3.3 & 0 & 0.0 & 29 & 96.7 & 0 & 0.0 \\
\hline Measuring blood pressure & 15 & 50.0 & 8 & 26.7 & 7 & 23.3 & 0 & 0.0 \\
\hline measuring body temperature & 16 & 53.3 & 3 & 10.0 & 11 & 36.7 & 0 & 0.0 \\
\hline $\begin{array}{l}\text { Assessment of nurse's continuous monitoring and } \\
\text { recording are followed surgery practice } \\
\text { observation checklist about post-operative care } \\
\text { of high tibial osteotomy surgery }\end{array}$ & 9 & 30.0 & 8 & 26.7 & 13 & 43.3 & 0 & 0.0 \\
\hline Oropharngeal suction if needed & 6 & 20.0 & 1 & 3.3 & 23 & 76.7 & 0 & 0.0 \\
\hline Assess indwelling urinary catheter & 19 & 63.3 & 7 & 23.3 & 4 & 13.3 & 0 & 0.0 \\
\hline Check IV infusion if needs change & 11 & 36.7 & 10 & 33.3 & 9 & 30.0 & 0 & 0.0 \\
\hline wound care. & 1 & 3.3 & 2 & 6.7 & 27 & 90.0 & 0 & 0.0 \\
\hline Neurovascular assessment & 4 & 13.3 & 3 & 10.0 & 23 & 76.7 & 0 & 0.0 \\
\hline
\end{tabular}




\begin{tabular}{|c|c|c|c|c|c|c|c|c|}
\hline \multirow[t]{2}{*}{ Variables } & \multicolumn{2}{|c|}{$\begin{array}{c}\text { Done } \\
\text { correct }\end{array}$} & \multicolumn{2}{|c|}{$\begin{array}{c}\text { Done } \\
\text { incorrect }\end{array}$} & \multicolumn{2}{|c|}{ Not done } & \multicolumn{2}{|c|}{ NA } \\
\hline & No. & $\%$ & No. & $\%$ & No. & $\%$ & No. & $\%$ \\
\hline $\begin{array}{l}\text { Assessing patients gastrointestinal function } \\
\text { auscultator peristaltic movement }\end{array}$ & 13 & 43.3 & 5 & 16.7 & 12 & 40.0 & 0 & 0.0 \\
\hline Assess patient's elimination & 13 & 43.3 & 2 & 6.7 & 14 & 46.7 & 1 & 3.3 \\
\hline \multicolumn{9}{|l|}{ Routine post-operative care } \\
\hline : relieving pain & 4 & 13.3 & 5 & 16.7 & 21 & 70.0 & 0 & 0.0 \\
\hline transfer to wheelchair & 3 & 10.0 & 4 & 13.3 & 23 & 76.7 & 0 & 0.0 \\
\hline using of knee brace & 2 & 6.7 & 0 & 0.0 & 28 & 93.3 & 0 & 0.0 \\
\hline Using of knee immobilizer & 0 & 0.0 & 3 & 10.0 & 27 & 90.0 & 0 & 0.0 \\
\hline Using of cold application & 2 & 6.7 & 0 & 0.0 & 28 & 93.3 & 0 & 0.0 \\
\hline Continuous passive motion devices (CPM) & 6 & 20.0 & 4 & 13.3 & 20 & 66.7 & 0 & 0.0 \\
\hline Range of motion exercises (ROM) & 4 & 13.3 & 4 & 13.3 & 22 & 73.3 & 0 & 0.0 \\
\hline Using of crutches & 8 & 26.7 & 4 & 13.3 & 18 & 60.0 & 0 & 0.0 \\
\hline Avoid post-operative complication & 12 & 40.0 & 4 & 13.3 & 14 & 46.7 & 0 & 0.0 \\
\hline $\begin{array}{l}\text { Assessment of nurse's about patient take } \\
\text { sufficient instruction before discharge practice } \\
\text { observation checklist about post-operative care } \\
\text { of high tibial osteotomy surgery }\end{array}$ & 8 & 26.8 & 4 & 14.6 & 18 & 58.5 & 0 & 0.1 \\
\hline
\end{tabular}

Table (5):Relationship between total practice level of the studied nurses and socio-demographic characteristics.

\begin{tabular}{|c|c|c|c|c|c|c|c|}
\hline \multirow{3}{*}{ Variables } & \multicolumn{6}{|c|}{ Level of practice } & \multirow{3}{*}{ P. value } \\
\hline & \multicolumn{2}{|c|}{ Done correct $(n=8)$} & \multicolumn{2}{|c|}{ Done incorrect $(n=4)$} & \multicolumn{2}{|c|}{ Not done $(n=18)$} & \\
\hline & No. & $\%$ & No. & $\%$ & No. & $\%$ & \\
\hline \multicolumn{8}{|l|}{ Sex } \\
\hline Male & 1 & 12.5 & 2 & 50.0 & 2 & 11.1 & \multirow{2}{*}{0.157} \\
\hline Female & 7 & 87.5 & 2 & 50.0 & 16 & 88.9 & \\
\hline \multicolumn{8}{|l|}{ Marital status } \\
\hline Single & 0 & 0.0 & 0 & 0.0 & 1 & 5.6 & \multirow{4}{*}{0.898} \\
\hline Married & 8 & 100.0 & 4 & 100.0 & 15 & 83.3 & \\
\hline Divorced & 0 & 0.0 & 0 & 0.0 & 1 & 5.6 & \\
\hline Widow or widower & 0 & 0.0 & 0 & 0.0 & 1 & 5.6 & \\
\hline \multicolumn{8}{|l|}{ Level of education } \\
\hline Diploma of nursing & 7 & 87.5 & 2 & 50.0 & 12 & 66.7 & \multirow{4}{*}{0.073} \\
\hline $\begin{array}{l}\text { Special diploma of } \\
\text { nursing }\end{array}$ & 0 & 0.0 & 2 & 50.0 & 1 & 5.6 & \\
\hline Technical nursing & 1 & 12.5 & 0 & 0.0 & 1 & 5.6 & \\
\hline Bachelor of nursing & 0 & 0.0 & 0 & 0.0 & 4 & 22.2 & \\
\hline \multicolumn{8}{|l|}{ Years of experience } \\
\hline $1-5$ years & 0 & 0.0 & 0 & 0.0 & 3 & 16.7 & \multirow{2}{*}{0.329} \\
\hline$<5$ years & 8 & 100.0 & 4 & 100.0 & 15 & 83.3 & \\
\hline
\end{tabular}


Table(6): Percentage distribution opinions of nurses regarding the basic competencies required for postoperative nursing care standards for high tibial osteotomy surgery.

\begin{tabular}{|l|c|c|c|c|}
\hline \multicolumn{1}{|c|}{ Variables } & \multicolumn{2}{|c|}{ Agree } & \multicolumn{2}{c|}{ Disagree } \\
\cline { 2 - 4 } & No. & $\%$ & No. & $\%$ \\
\hline $\begin{array}{l}\text { Ensures that the orthopedic surgery Department environment are ready to receive } \\
\text { the high tibial osteotomy patient }\end{array}$ & 26 & 86.7 & 4 & 13.3 \\
\hline $\begin{array}{l}\text { Ensure that the orthopedic Surgery Department environment is safe to receive high } \\
\text { tibial osteotomy patient: }\end{array}$ & 28 & 93.3 & 2 & 6.7 \\
\hline $\begin{array}{l}\text { Ensure that continuous monitoring and recording are followed for post-operative } \\
\text { patients }\end{array}$ & 27 & 90.0 & 3 & 10.0 \\
\hline Ensures that all infection control measures are properly followed in all procedures & 28 & 93.3 & 2 & 6.7 \\
\hline Ensures that all health team are properly attired for patient care & 28 & 93.3 & 2 & 6.7 \\
\hline $\begin{array}{l}\text { Ensure that safety for each patient during transportation from operating room to } \\
\text { unit }\end{array}$ & 28 & 93.3 & 2 & 6.7 \\
\hline $\begin{array}{l}\text { Ensures that all staff members (health team) follow ethics and patient rights in the } \\
\text { orthopedic surgery department }\end{array}$ & 27 & 90.0 & 3 & 10.0 \\
\hline
\end{tabular}

Table (1): shows that; the majority of nurses $56.7 \%$ their age ranged from $20-40$ years. $90 \%$ of them were married. $90 \%$ of them had ranged from 5-10 years of experience. $70 \%$ of them had a diploma of nursing. As regard to previously of attended training programs, it was found that $96.7 \%$ were not attending training program about high tibial osteotomy surgery. Table (2): shows that; more than half of nurses $(53.3 \%)$ had a good level of knowledge as regarding high tibial osteotomy.

Table (3): shows that; significance difference between knowledge level and years of experience.

Table (4) :shows that; the majority of nurses had not done hand washing ,immediate post-operative care ,routine post-operative care and not take patient sufficient instruction before discharge practice.

Table (5) shows that; there significance difference between practice and level of education.

Table(6): shows that the majority of nurses agree with basic post-operative nursing care standards.

\section{Discussion}

The discussion was cover the main result findings as follow:

The results of the present study showed that the majority of the nurses their ages ranged from 20-40 years, married, female, and have diploma of nursing, more than half of them, their experiences more than 5 years. All of them had no in-service training courses related to high tibial osteotomy.

Ahmed, (2013); in the same line with the current study findings conducted a study in neurosurgery department at Assiut University Hospital entitled "Developing nursing care standards for patients post disectomy" .As well, Ahmed (2014); conducted a study in cardiothoracic surgery department at Assiut university hospital entitled coronary artery bypass grafting "Effect Of Developing and Implementing Nursing Care Standards on Patients Outcome" who mentioned that the majority of nurses were aged from 20-40 years. The majority of nurses were female and nursing diploma and the majority of them had no inservice training courses.

Marquis \& Huston (2010): stated that education and training are two components of staff development that occur after an employees' indoctrination (which refers to planned, guided adjustment of employee to the organization and work environment). The staffs' knowledge level and capabilities are a major factor in determining the number of staff required to carry out unit goals. The better trained and more competent the staff, the fewer staff required, which in turn saves the organization money and rise reproductively.

As regard knowledge about high tibial osteotomy, the majority of nurses answered incompletely as regarding indication and contraindications of the high tibial osteotomy . the majority of nurses answered complete correct as regarding definition of the high tibial osteotomy, types of the high tibial osteotomy, a complication of the high tibial osteotomy. This result may be attributed to insufficient courses related to high tibial osteotomy included in their undergraduate curriculum of nursing education. Most nurses stated that their knowledge gained while working with patients. Also, there is no Arabic source for updating and continuing their education.

This result contradicted with Xyrichis \& Lowton, (2007) who stated that Multiprofessional education within tissue viability is vital if patients are to receive optimum care and this education should commence at the undergraduate level. However, after qualifying, time pressures within healthcare areas can prove to be a barrier for staff wishing to access courses. Staff 
often rely on advice from peers who may themselves not have accessed the most up-to-date information which can prevent the development of evidencebased interventions.

Furthermore, the result of this study revealed that more than half of nurses had a good level of knowledge as regarding high tibial osteotomy. A minority of nurses had a poor level of knowledge as regarding high tibial osteotomy.

The majority of nurses who their age 20-40 years and diploma nurses had a good level of knowledge about high tibial osteotomy .

The present study showed that fair knowledge was among group less than 5 years of experience. This might be due to that nurse who have more experience will be responsible for administrative and managerial activities. This finding was in accordance with Mostafa, (2012), entitled as " Developing standards of post-operative nursing interventions for lower limb amputated patients" who found that nurses who their years of experience >5years had fair level of knowledge

The present study revealed that good knowledge was among diploma nursing. This result disagree with Aboulwafa, (2009) who found that high level of knowledge regarding universal infection control precautions those who have Bachelor of science in nursing because of number of bachelor of science in nursing are minimal.

This result also agreed with Aiken, (2003) who showed that staffing with baccalaureate-educated RNs is associated with improved patient safety and positive patient outcomes. One study showed a fiveper-cent decrease in the risk of patient death for every 10 -per-cent increase in the proportion of hospital RNs holding degrees. Better patient outcomes also mean cost savings for the health-care system.

This result disagrees with Dianne McMahon, (2011) stated that the nurse is responsible and accountable for the quality of nursing care given to patients. The single most important protective strategy for the nurse is to be a knowledgeable and safe practitioner of nursing and to meet the standards of care with all patients. Nurses are empowered by the SOC and the trust of the physician and the patient to ensure quality care.

As regard, this study, the majority of nurses did not give complete post-operative interventions for high tibial osteotomy patients. This may be due to that all nurses did not have enough knowledge about nursing care, absence of a standard of nursing care related to high tibial osteotomy, in-service education programs, and training of newly recruited nurses allowed them to learn from each other without improvement in the level of performance. Moreover, lack of existence of a system for supervision and evaluation of nurses' practice.

Furthermore, this is in accordance with Mustafa (1999) \& Dawooda, (2010) who mentioned that nurses are lacking in theoretical and practical skills needed for patient assessment. Other factors that affect nurse's practice are the shortage of the nurse's number, and overlapping of nursing activities especially in morning shifts due to absence and ignorance of clear job description. This interpretations in the same line with Ead, (2007) who stated that lack of nurse' practice related to absence of definite job description and policy . This result contradicted with Marquis \& Huston (2010)who reported that each organization and profession must set standards and objectives to guide individuals and practitioners in performing safe and effective care. Also not only must standards exist, but leader and mangers also must see that subordinates know and understand the standards and employee must be aware that their performance will be measured in terms of their ability to meet the established standards.

Badran, (2010); in the same line with current study findings conducted a study in the Nephrology unit and Nephrology and Urology center, Mansoura University. Entitled "Establishing standards of pre and post operative nursing interventions for patients undergoing kidney transplantation.

As regard to ensuring that the orthopedic surgery department environment are ready to receive the high tibial osteotomy patients. The majority of nurses had agreed about preparing orthopedic surgery department with the necessary equipment, Preparing the car /table with the instrument according to patient condition, preparing patient room, components of orthopedic surgery department. This finding may be related to that some nurses had long years of experience. So they aware of the necessary equipment and preparation for high tibial osteotomy patient, others believe that structure standard difficult to be available.

This result was in line with Fortunato, (2007) who stated that the nurses should prepare the basic equipment for receiving post operative high tibial osteotomy patients .

The present study revealed that majority of nurses had agreed about ensuring that the orthopedic surgery department environment are safe to receive high tibial osteotomy patient. This competency includes identifying your patient, Prevention patients fall by side rails, prevention patients fall by hand rails, reporting accidents and errors, Maintaining safe environment post-operative They said that no available resources to maintain safety. 
The result of the present study is in the same line with Ahmed,(2015) in titled as" Developing Nursing Care Standards for Venous Thromboembolism in Orthopedic Surgery Patients" who stated that the majority of nurses had agreed with continuous monitoring and recording for post-operative high tibial osteotomy patients which included immediate post operative period, routine post operative period, avoid post operative complications, discharge advice. This result is in agreement with Ponsky, (2002) who mentioned that postoperative care is the management of a patient after surgery. This includes care given during the immediate postoperative period, both in the operating room and post-anesthesia care unit (PACU), as well as during the days following surgery.

Furthermore, Lubin \& Michael, (2003) reported that Postoperative care involves assessment, diagnosis, planning, intervention, and outcome evaluation. The extent of postoperative care required depends on the individual's pre-surgical health status, type of surgery, and whether the surgery was performed in a day-surgery setting or in the hospital. Patients who have procedures done in a day-surgery center usually require only a few hours of care by health care professionals before they are discharged to go home. If post anesthesia or postoperative complications occur within these hours, the patient must be admitted to the hospital. Patients who are admitted to the hospital may require days or weeks of postoperative care by hospital staff before they are discharged.

Infection control tasks were accepted by the majority of nurses. This can be due to attending in-service training programs related to infection control measures. This competency included the following criteria principle of aseptic technique in all procedure, identify and supervise methods of disinfecting (walls, floor, chair, nursing room) and using universal precaution

This result congruent with Kelly, (2011) who reported that "An effective facility-wide infection prevention and control program is composed of many components and interventions that can reduce the risk of infection in surgery patients. This includes an understanding of the surgical population and the associated risk factors, effective methods for case finding, expertise in the analysis of data, effective communication of outcomes, and implementation of evidenced-based strategies to improve outcomes. Central to this theme is collaboration. In order to ensure patient safety and optimum patient outcomes, surgeons, preoperative staff, nurses, and all members of the healthcare team must work together to implement evidence-based practices that minimize the risk of infection.
Moreover, in the present study that nurses had poor knowledge related to methods of disinfection. These findings appear to be due to that nurse's think that was the responsibility of head nurses and also, they had no standards or written protocols related to high tibial osteotomy in the department.

These findings in contrast with Magnum (2001) who stated that proper cleaning reduces the number of exogenous microorganisms in the environment, and helps to reduce air born contaminants that may travel on dust and settle on surfaces. In addition, cleaning should be performed on scheduled basis and should provide a safe, visibly clean environment for patients to protect patient and staff.

University of Virginia health system (UVAHS) professional nursing staff organization (2011) assured that Environmental Services' work to maintain cleanliness of the patient care and work environments is key to infection control and safety as well as the pleasant atmosphere of the patient care areas. Significant feedback on the part of nursing staff and management was instrumental in the institution deciding to change its contract to another vendor. Also, with the main hospital building constructed in 1989, remodeling, renovation and expansion are constantly underway to improve space and services. Nursing staff and managers have major input into the renovation designs, to help identify the best pattern of patient flow, ensure space for patient care and staff/administrative functions, and promote the convenient placement of fixtures and resources even improving lighting levels.

In relation to ensuring that health team is properly attired for patient care, the majority of nurses agreed about this competency. In this context, Murray(2001) stated that personal protective equipment (PPE) is designed to protect the skin and the mucous membranes of the eyes, nose, and mouth of dental health-care personnel from exposure to blood or other potentially infectious material.

Caruthers, (2008) mentioned that sterile gowns and gloves are worn to prevent the migration of microbes from the skin and scrub attire of the sterile team member to the sterile field. Additionally, sterile attire prevents blood and body fluids from contaminating the team member. Lastly, sterile attire aids in preventing surgical site infections (SSI) by allowing team members to work within the sterile field handling sterile below is a reminder to surgical personnel.

Based on the present study, the majority of nurses had agreed about ensuring that safety for each patient during transportation from operating room to unit. This result was in agreement with Wilson,( 2007) who stated that Staff orientation and training improved patient outcomes during transport. A 
transport team might include nurses, paramedics, respiratory therapists, and physicians, depending on the stability of the patient.

Gutterman, (2007) mentioned that safety measures are implemented to prevent injury to both patient and staff members. The staff uses good body mechanics and assistive devices, such as draw sheets or body rollers, to allow proper weight distribution of the patient. The stretcher wheels are locked to prevent movement. The patient is always lifted from the table, as opposed to being dragged or pulled with draw sheets, to prevent skin irritation or shearing. The nurse applies stretcher belts (restraints) prior to transport. Also, the head of the stretcher is elevated, side rails are raised, and the placement of tubes and drains is confirmed

Ensuring that all staff follows ethics and patient's rights in the orthopedic surgery department was agreed by majority of studied nurses. This result agreed with the Canadian Nurses Association's Code of Ethics for Registered Nurses. Code of Ethics is a statement of the ethical values of nurses and of nurses' commitments to persons with health-care needs and persons receiving care. It is intended for nurses in all contexts and domains of nursing practice and at all levels of decision-making. It is developed by nurses for nurses and can assist nurses in practicing ethically and working through ethical challenges that arise in their practice with individuals, families, communities and public health systems.

Today's practicing nurse must be aware of nursing standards, legal issues in nursing, legal limits of nursing and legal liabilities. Otherwise, he or she could be the first person to be penalized from a legal standpoint. Legal responsibilities in nursing practice are growing in importance day by day. Legal accountability is an essential concept of professional nursing practice that can pose a threat to a nurse's career if he or she is uninformed of the law. Legal issues confronting practicing nurses today are legion. The nurse need not view the law not with apprehension but as a helpful adjunct to the practice of nursing. (Dianne McMahon, (2011)

Finally, it seems logic to say that, besides to improving quality of life, early detection, and prevention of complication, it was found that application of post operative standards is very important for high tibial osteotomy patients, based on the result of the present study, which indicated the applicability of post-operative nursing care standards.

\section{Conclusion}

Based on finding of this study, it can be concluded that

- More than half of nurses had good knowledge regarding standards of post operative interventions for high tibial osteotomy patients.

- Nurses showed inadequacy in their practice about standards of post operative interventions for high tibial osteotomy patients.

- The majority of nurses agree with basic postoperative nursing care standards.

\section{Recommendations}

Based on the findings of the present study the following recommendations are suggested

- Application of the nursing care standards for postoperative high tibial osteotomy patients

- Planning for an in-service training program for health care providers is important in the orthopedic surgery department.

- Motivation and financial rewards to encourage the orthopedic surgery department nurses to do their best.

- Nursing standards must be designed and communicated to all nursing staff in each hospital to improve care rendered.

- Evaluate the effect (outcome) of nursing care standards on post operative high tibial osteotomy patients.

\section{References}

1. Aalderink K., Shaffer M., Amendola A., (2010); Rehabilitation Following High Tibial Osteotomy. Clin Sports Med. 29: 291-301.

2. Abolwafa N., (2009): Assessment of nurses' knowledge and performance related to infection control in the neonatal units at Elminia City Hospitals.

3. Ahmed, A., (2013) : Developing nursing care standards for patient with disectomy at Assuit University Hospital. Thesis Submitted for Partial Fulfilment of the Requirement of Master Degree in Medical Surgical Nursing, faculty of nursing Assiut University.

4. Ahmed, G., (2014) :Coronary Artery Bypass Grafting Effect of Developing and Implementing Nursing Care Standards on Patients Outcome at Assuit University Hospital . Thesis Submitted for Partial Fulfilment of the Requirement of Doctor Degree in Medical Surgical Nursing, faculty of nursing Assiut University .

5. Ahmed, M., (2015): Devoloping Nursing Care Standards For Venous Thromboembolism in Orthopedic Surgery Patients. Thesis Submitted for Partial Fulfilment of the Requirement of 
Master Degree in Adult Nursing, faculty of nursing Assiut University.

6. Aiken, L., Clarke, S., Cheung, R., Sloane, D., \& Silber, J., (2003). Educational levels of hospital nurses and surgical patient mortality. Journal of the American Medical Association1617-1623. Am;71:245-248. Copyright $@ 2005$ by the American Academy of Orthopaedic Surgeons Vol 13 No 4.

7. Amendola A., Bonasia D., (2010): Results of high tibial osteotomy: Review of the literature. Int Orthop;34(2):155- 160. Copyright $(2011$ by the American Academy of Orthopaedic Surgeons Vol 19 No 10.

8. Badran. H.,(2010): Establishing Standards of pre and post operative nursing interventions for patients undergoing kidney transplantation.

9. Brosset T., Pasquier G., Migaud H., Gougeon F., (2011); Opening Wedge High Tibial Osteotomy Performed Without Filling the Defect but with Locking Plate Fixation (Tomofix) and Early Weight-Bearing: Prospective Evaluation of Bone Union, Precision, and Maintenance of Correction in 51 Cases. Orthopaedic \& Traumatology: Surgery and Research; 97: 705711.

10. Brouwer R., Bierma-zeinstra, S., van Raaij T., Verhaar, J., (2006): Osteotomy for medial compartment arthritis of the knee using a closing wedge or an opening wedge controlled by a puddu plate: A one-year randomized, controlled study. The Journal of Bone and Joint Surgery, p.p:1454-1459.

11. Caruthers B., Junge T., Long J., Price B., (2008): Surgical case management.

12. Dawooda T., (2010): Esablishing Basic Standards of Nursing Care for faciomaxillary patients Undergoing Surgeries.

13. Dianne McMahon (2011): HG.Org World Wide Directories.HGExperts.com.

14. Dianne McMahon, (2010), www.medinine net.com.

15. Ead A., (2007):Developing Standards of Intraoperative Nursing Interventions for General Surgery.

16. Fortunato N., (2007): operating room technique, 11 edition, St louis : Mosby .

17. Gutterman (2007) : responding to the needs of the per operative patient, chapter 30, pp(769).

18. Hartford, James M., Hester P., Watt, Phil M., Hamilton D., Rohmiller M., Pienkowski D.,(2003): Biomechanical superiority of plate fixation for proximal tibial osteotomy. Clinical Orthopaedics and Related Research.;412:125130. Copyright (C) 2008The Brigham and
Women's Hospital, Inc., Department of Rehabilitation Services.

19. Hoell S., Suttmoeller J., Stoll V., Fuchs S., Gosheger G., (2005) The high tibial osteotomy, open versus closed wedge, A comparison of methods in 108 patients. Archives of Orthopedic Trauma Surgery.;125:638-643. Copyright (C) 2008The Brigham and Women's Hospital, Inc., Department of Rehabilitation Services.http://currentnursing.com/reviews/ nursing_standards.htm.

20. Janice R., CeliaLH, Elizabeth N., Helen K., Martin A.B.,(2009): Managing and coordinating Nursing care, $5^{\text {th }} \mathrm{e}$ ed , chapter 7,pp (359-264)

21. Kelly M., Pyrek (2011): infection control today online library, environmental hygiene.

22. Lubin, Michael F., Kenneth Walker, \& Robert B., Smith, E.,(2003): Medical Management of the Surgical Patient. 4th ed. Cambridge, UK: Cambridge University Press.

23. Mangum S,Gruendemann B.(2001): infection prevention in surgical settings, WB Saunders company.

24. Marquis L., Bessie\& Huston J., Carol, (2010) : Leader ship roles\& management functions in nursing, 6 ed , Lippincott Williams and Wilkins, Hong Kong P. 371.

25. Mostafa, N., (2012): Developing standards of post-operative nursing intervention for lower limb amputated patients. Thesis Submitted in Partial Fulfillment of the Requirements for The Master Degree in Adult Nursing (Medical Surgical Nursing), faculty of nursing Assiut University.

26. Murray C., Burke F., McHugh S., (2001): an assessment of the incidence of punctures in latex and non-latex dental examination gloves in routine clinical practice. PP: 377-380.

27. Mustafa. G., (1999).Baccalaureate Nursing Standards Experience in Critical care in Egyptian Exploratory Study. The bulletin of the High Institute of Public Health.

28. Ponsky, Jeffrey, Michael Rosen, Jason Brodsky, M., Frederick Brody, M., (2002): The Cleveland Clinic Guide to Surgical Patient Management, 1st ed. Philadelphia: Mosby.

29. Rossi R, Bonasia D., Amendola A., (2011): The Role of High Tibial Osteotomy in the Varus knee. Journal of the American Academy of Orthopedic Surgeons, ch(19),p.p:590-599 Vol 19 No 10.

30. University of Virginia health system (UVAHS) (2011): ensuring safe practice environment. EPINet / UVA's international health care worker safety center. 
31. Wilson, P., (2007): "Safe Patient Transportation: Nurses Can Make a Difference." Nursing Times 94(26): 66-67.

32. Wolcott M., Traub S., Efird C., (2010) :(high Tibial Osteotomy in the Young Active Patient . International Orthopedics ‘'ch ) (34) ‘(p.p.166161.

33. Wright, John M., Crockett, Heber C., Slawski, Daniel P., Madsen, Mike W.,Windsor, Russell E.,(2005): High tibial osteotomy. Journal of American Academy of Orthopedic Surgeons Vol 13 NO4

34. Xyrichis A., Lowton K., (2007): what fosters or prevents interprofessional team working in primary and community care? A literature review. 